\title{
Henryk M. Wisniewski and the amyloid theory of Alzheimer's disease
}

\author{
Colin L. Masters ${ }^{\mathrm{a}, \mathrm{b}}$ and Konrad Beyreuther ${ }^{\mathrm{c}, *}$ \\ ${ }^{a}$ Department of Pathology, The University of \\ Melbourne, Parkville, Victoria, Australia \\ ${ }^{\mathrm{b}}$ The Mental Health Research Institute of Victoria, \\ Australia \\ ${ }^{\mathrm{c}}$ Center for Molecular Biology $(\mathrm{ZMBH})$, The \\ University of Heidelberg, Heidelberg, Germany
}

\section{Introduction}

The amyloid theory of Alzheimer's disease (AD) is now the dominant paradigm for the etiology of this particular neurodegenerative disorder, and Henryk Wisniewski played a major role in its elaboration. Together with Robert Terry, in the early 1970's, they were in a position to take advantage of the electron microscope to give a fine structural account of the appearances of $\mathrm{A} \beta$ amyloid deposition in the AD brain. Wisniewski brought his characteristic flair to these descriptive analyses, best summarised in a review article published in 1973 8. That review has come to represent the watershed between the classic morphologic approach (commencing with Bloqc and Marinesco in 1892) and the current molecular biological era. It is worth re-reading in detail, since it sets out clearly many of the paradoxes of $\mathrm{A} \beta$ deposition that still require clarification. Let's summarize Wisniewski's analysis of the amyloid theory as it stood in 1973, and then see where his ideas have led us today.

Wisniewski started his analysis with the observation that the classic morphologic approach allowed for three types of plaques:

a) typical plaques with a central core of amyloid surrounded by rods, granules and reactive cells;

* Correspondence to: Center for Molecular Biology (ZMBH), The University of Heidelberg, D-69120, Germany. Tel.: +496221546 845; Fax: +49 6221545 891; E-mail: k.beyreuther@zmbh.uniheidelberg.de. b) primitive plaques without a central amyloid core; and

c) compact ("burned-out") plaques with a central core alone.

Previously, light microscopists had been unable to determine the cellular origins of the rods and granules around a typical plaque. Primitive plaques would have covered the amorphous and "cotton-wool" plaques that are currently in vogue today. The attribution of a "burned-out" nature to a plaque without neuritic or cellular reactive changes was a bold interpretative step. The relationship of intracellular neurofibrillary changes to these plaques was acknowledged to be a major question.

The advent of electron microscopy therefore permitted a precise definition of the rods and granules around a plaque, and thus suggested to Wisniewski and Terry that plaques formed in the following sequence: degeneration of neuritic terminals; attraction of reactive cells; and subsequent deposition of amyloid. To emphasise this temporal sequence, they proposed to change the terminology of "senile plaque" to "neuritic plaque", and echoed McMenemey's suggestion that "the plaque should not be accepted as a phenomenon of pure aging, but rather as a manifestation of disease". In addition to describing the fine structure of the neuritic elements and reactive cells surrounding and interweaving with the amyloid deposits, Wisniewski also drew attention to neuritic changes in the neuropil in the absence of close proximity to the larger deposits of amyloid. When numerous, however, the neuritic changes were accompanied by small bundles or wisps of extracellular amyloid. Within neurites, elements of the paired helical filaments of the neurofibrillary tangle were observed for the first time, thus linking this intracellular phenomenon to the process of neurofibrillary tangle formation in the cytoplasm and peri-somal areas of neurons.

For the morphologists of 1973, the central question "would seem to be which of the three components arrives first on the scene and is the nidus of formation? 
Both macrophages and astocytes may be assumed to be reactive and secondary. We are left, therefore, with either neurites or amyloid". In contrast to the amyloid theory of Divry and Schwartz (that the amyloid deposition caused neurodegeneration), Wisniewski and Terry were inclined to the alternate idea that neuritic change caused the amyloid formation: "Our inference is that aggregates of degenerating neurites induce the local deposition of amyloid, and therefore that the neurites are the nidus of plaque formation".

The 1970's marked the beginnings of the biochemical unravelling of the amyloid, beginning with studies of Nikaido and Austin, Glenner, Allsop and Landon, Bobin and Wisniewski, Selkoe, and ourselves. The purification, amino acid sequencing, and finally the cloning of the amyloid- $\beta$ protein precursor $(\mathrm{A} \beta \mathrm{PP})$ has permitted the amyloid theory of AD to develop at a rapid pace. We stand today at a point where the evidence is compelling that $\mathrm{A} \beta$ amyloid lies in the central pathway of the etiology of AD. The dominantly inherited forms of $\mathrm{AD}$ show clearly that mutations in the $\mathrm{A} \beta \mathrm{PP}$ gene or in the associated processing machinery (the presenilins) are sufficient to allow for the over-production of $\mathrm{A} \beta 42$ and thereby cause AD. The genetically inherited risk factors (ApoE, for example) also appear to operate through the $\mathrm{A} \beta$ pathway. The genetically engineered transgenic mice in which $\mathrm{A} \beta$ amyloid deposition occurs (albeit without neurofibrillary degeneration) also serve to emphasize this central amyloidogenic pathway.

How then did Wisniewski adapt his ideas and hypotheses in the light of the flood of information that emerged over the last 20 years? For a start, he continually championed the role of amyloid in AD pathogenesis, and stimulated much debate over its primary or secondary role. He never fully gave up the idea that the vascular system or reactive microglia had some major role to play. Recent discoveries on the clearance of $\mathrm{A} \beta$ deposits from the extraparenchymal spaces of the brain following immunization with $\mathrm{A} \beta$ itself have borne out this approach, notwithstanding the secondary role of microglia that has been demonstrated by this phenomenon. Concerning the idea that neuritic change induced amyloid deposition, it is now clear from the transgenic mouse models that the reverse situation is operative ... but a caveat remains over the failure of these animal models to generate intracellular paired helical filaments. Wisniewski's key observations on the presence of these abnormal filamentous aggregates within the (pre-synaptic) neurites of the AD brain may yet prove to be the missing link between $\mathrm{A} \beta$ deposition and neurite formation.
Do the three types of amyloid plaque (typical, primitive and compact) have any pathogenic significance? Their replication, to a variable extent, in the transgenic mouse models would suggest that the spectrum of plaque morphology is determined largely by the kinetics of $\mathrm{A} \beta$ amyloid formation, deposition, and clearance. But to the extent that the type of plaque is determined by the degree of neuritic change, a salutary lesson may still be gleaned from Wisniewski's analysis. He pointed out that the Divry-Schwartz concept of the amyloid theory came "as an indivisible three-part package". This nexus between the $\mathrm{A} \beta$ amyloid, neurites, and reactive cells needs to be kept in mind as we take the final steps towards a coherent theory of Alzheimer's neurodegeneration.

\section{References}

[1] I. Klatzo, H. Wisniewski and E. Streicher, Experimental production of neurofibrillary degeneration, J. Neuropath. Exp. Neurol. 24 (1965), 187-199.

[2] H. Wisniewski, O. Narkiewicz and K. Wisniewska, Topography and dynamics of neurofibrillar degeneration in aluminum encephalopathy, Acta Neuropathol. (Berl.) 9 (1967), 127-133.

[3] M.L. Shelanski and H. Wisniewski, Neurofibrillary degeneration induced by vincristine therapy, Arch. Neurol. 20 (1969), 199-206.

[4] H. Wisniewski, A.B. Johnson, C.S. Raine, W.J. Kay and R.D. Terry, Senile plaques and cerebral amyloidosis in aged dogs. A histochemical and ultrastructural study, Lab. Invest. 23 (1970), 287-296.

[5] H. Wisniewski, R.D. Terry and A. Hirano, Neurofibrillary pathology, J. Neuropathol. Exp. Neurol. 29 (1970), 163-176.

[6] H.M. Wisniewski, J.M. Coblentz and R.D. Terry, Pick's disease. A clinical and ultrastructural study, Arch. Neurol. 26 (1972), 97-108.

[7] H.M. Wisniewski, B. Ghetti and R.D. Terry, Neuritic (senile) plaques and filamentous changes in aged rhesus monkeys, $J$. Neuropathol. Exp. Neurol. 32 (1973), 566-584.

[8] H.M. Wisniewski and R.D. Terry, Reexamination of the pathogenesis of the senile plaque, in: Progress in Neuropathology, H.M. Zimmerman, ed., Grune \& Stratton, New York, 1973, pp. $1-26$.

[9] I. Grundke-Iqbal, A.B. Johnson, H.M. Wisniewski, R.D. Terry and K. Iqbal, Evidence that Alzheimer neurofibrillary tangles originate from neurotubules, Lancet 1 (1979), 578-580.

[10] H.M. Wisniewski, J.A. Sturman and J.W. Shek, Aluminum chloride induced neurofibrillary changes in the developing rabbit a chronic animal model, Ann. Neurol. 8 (1980), 479490.

[11] P.A. Merz, R.A. Somerville, H.M. Wisniewski and K. Iqbal, Abnormal fibrils from scrapie-infected brain, Acta Neuropathol. 54 (1981), 63-74.

[12] P.A. Merz, H.M. Wisniewski, R.A. Somerville, S.A. Bobin, C.L. Masters and K. Iqbal, Ultrastructural morphology of amyloid fibrils from neuritic and amyloid plaques, Acta Neuropathol. 60 (1983), 113-124. 
[13] H.M. Wisniewski, P.A. Merz and K. Iqbal, Ultrastructure of paired helical filaments of Alzheimer's neurofibrillary tangle, J. Neuropathol. Exp. Neurol. 43 (1984), 643-656.

[14] A.W. Vorbrodt, A.S. Lossinsky, H.M. Wisniewski, R. Suzuki, T. Yamaguchi, H. Masaoka and I. Klatzo, Ultrastructural observations on the transvascular route of protein removal in vasogenic brain edema, Acta Neuropathol. 66 (1985), 265-273.

[15] H.M. Wisniewski and G.Y. Wen, Substructures of paired helical filaments from Alzheimer's disease neurofibrillary tangles, Acta Neuropathol. 66 (1985), 173-176.

[16] I. Grundke-Iqbal, K. Iqbal, M. Quinlan, Y.C. Tung, M.S. Zaidi and H.M. Wisniewski, Microtubule-associated protein tau. A component of Alzheimer paired helical filaments, $J$. Biol. Chem. 261 (1986), 6084-6089.

[17] R. Rubenstein, R.J. Kascsak, P.A. Merz, H.M. Wisniewski, R.I. Carp and K. Iqbal, Paired helical filaments associated with Alzheimer disease are readily soluble structures, Brain Res. 372 (1986), 80-88

[18] H.M. Wisniewski, R.C. Moretz and K. Iqbal, No evidence for aluminum in the etiology and pathogenesis of Alzheimer's disease, Neurobiol. Aging 7 (1986), 532-535.

[19] S.A. Bobin, J.R. Currie, P.A. Merz, D.L. Miller, J. Styles, W.A. Walker, G.Y. Wen and H.M. Wisniewski, The comparative immunoreactivities of brain amyloids in Alzheimer's disease and scrapie, Acta Neuropathol. 74 (1987), 313-323.

[20] N.K. Robakis, N. Ramakrishna, G. Wolfe and H.M. Wisniewski, Molecular cloning and characterization of a cDNA encoding the cerebrovascular and the neuritic plaque amyloid peptides, Proc. Natl. Acad. Sci. USA 84 (1987), 4190-4194; Proc. Natl. Acad. Sci. USA 84 (Oct. 1987), 7221.

[21] G. Szumanska, A.W. Vorbrodt, T.I. Mandybur and H.M. Wisniewski, Lectin histochemistry of plaques and tangles in Alzheimer's disease, Acta Neuropathol 73 (1987), 1-11.

[22] J. Rafalowska, M. Barcikowska, G.Y. Wen and H.M. Wisniewski, Laminar distribution of neuritic plaques in normal aging, Alzheimer's disease and Down's syndrome, Acta Neuropathol. 77 (1988), 21-25.

[23] A.W. Vorbrodt, D.H. Dobrogowska, Y.S. Kim, A.S. Lossinsky and H.M. Wisniewski, Ultrastructural studies of glycoconjugates in brain micro-blood vessels and amyloid plaques of scrapie-infected mice, Acta Neuropathol. 75 (1988), 277-287.

[24] M. Barcikowska, H.M. Wisniewski, C. Bancher and I. Grundke-Iqbal, About the presence of paired helical filaments in dystrophic neurites participating in the plaque formation, Acta Neuropathol. 78 (1989), 225-231.

[25] I. Grundke-Iqbal, K. Iqbal, L. George, Y.C. Tung, K.S. Kim and H.M. Wisniewski, Amyloid protein and neurofibrillary tangles coexist in the same neuron in Alzheimer disease, Proc. Natl. Acad. Sci. USA 86 (1989), 2853-2857.

[26] H.M. Wisniewski, C. Bancher, M. Barcikowska, G.Y. Wen and J. Currie, Spectrum of morphological appearance of amyloid deposits in Alzheimer's disease, Acta Neuropathol. 78 (1989), 337-347.

[27] H.M. Wisniewski, J. Wegiel, K.C. Wang, M. Kujawa and B. Lach, Ultrastructural studies of the cells forming amyloid fibers in classical plaques, Can. J. Neurol. Sci. 16 (1989), 535-542.

[28] K.S. Kim, G.Y. Wen, C. Bancher, C.M.J. Chen, V.J. Sapienza, H. Hong and H.M. Wisniewski, Detection and quantification of amyloid $\beta$-peptide with 2 monoclonal antibodies, Neurosci. Res. Comm. 7 (1990), 113-122.

[29] J. Wegiel and H.M. Wisniewski, The complex of microglial cells and amyloid star in three-dimensional reconstruction, Acta Neuropathol. 81 (1990), 116-124.
[30] H.M. Wisniewski, M. Barcikowska and E. Kida, Phagocytosis of $\beta / \mathrm{A}_{4}$ amyloid fibrils of the neuritic neocortical plaques, Acta Neuropathol. 81 (1991), 588-590.

[31] H.M. Wisniewski and J. Wegiel, Spatial relationships between astrocytes and classical plaque components, Neurobiol Aging 12 (1991), 593-600.

[32] J. Frackowiak, H.M. Wisniewski, J. Wegiel, G.S. Merz, K. Iqbal and K.C. Wang, Ultrastructure of the microglia that phagocytose amyloid and the microglia that produce $\beta$ amyloid fibrils, Acta Neuropathol. 84 (1992), 225-233.

[33] H.M. Wisniewski, J. Wegiel, K.C. Wang and B. Lach, Ultrastructural studies of the cells forming amyloid in the cortical vessel wall in Alzheimer's disease, Acta Neuropathol. 84 (1992), 117-127.

[34] H.M. Wisniewski and J. Wegiel, Migration of perivascular cells into the neuropil and their involvement in $\beta$-amyloid plaque formation, Acta Neuropathol. 85 (1993), 586-595.

[35] T. Pirttila, K.S. Kim, P.D. Mehta, H. Frey and H.M. Wisniewski, Soluble amyloid $\beta$-protein in the cerebrospinal fluid from patients with Alzheimer's disease, vascular dementia and controls, J. Neurol. Sci. 127 (1994), 90-95.

[36] H.M. Wisniewski, J. Frackowiak, A. Zoltowska and K.S. Kim, Vascular $\beta$-amyloid in Alzheimer's disease angiopathy is produced by proliferating and degenerating smooth muscle cells, Amyloid: Intl. J. Exp. Clin. Invest. 41 (1994), 8-16.

[37] H.M. Wisniewski and J. Wegiel, $\beta$-amyloid formation by myocytes of leptomeningeal vessels, Acta Neuropathol. 87 (1994), 233-241.

[38] P. Kasa, P. Szerdahelyi and H.M. Wisniewski, Lack of topographical relationship between sites of aluminum deposition and senile plaques in the Alzheimer's disease brain, Acta Neuropathol. 90 (1995), 526-531.

[39] E. Kida, K.E. Wisniewski and H.M. Wisniewski, Early amyloid- $\beta$ deposits show different immunoreactivity to the amino- and carboxy-terminal regions of beta-peptide in Alzheimer's disease and Down's syndrome brain, Neurosci. Lett. 193 (1995), 105-108.

[40] B. Mazur-Kolecka, J. Frackowiak and H.M. Wisniewski, Apolipoproteins E3 and E4 induce, and transthyretin prevents accumulation of the Alzheimer's $\beta$-amyloid peptide in cultured vascular smooth muscle cells, Brain Res. 698 (1995), 217-222.

[41] H.M. Wisniewski, J. Frackowiak and B. Mazur-Kolecka, In vitro production of $\beta$-amyloid in smooth muscle cells isolated from amyloid angiopathy-affected vessels, Neurosci. Lett. 183 (1995), 120-123.

[42] K. Fukuchi, L. Ho, S.G. Younkin, D.D. Kunkel, C.E. Ogburn, R.C. LeBoeuf, C.E. Furlong, S.S. Deeb, D. Nochlin, J. Wegiel, H.M. Wisniewski and G.M. Martin, High levels of circulating $\beta$-amyloid peptide do not cause cerebral $\beta$-amyloidosis in transgenic mice, Amer. J. Pathol. 149 (1996), 219-227.

[43] V.P. Chauhan, I. Ray, A. Chauhan, J. Wegiel and H.M. Wisniewski, Metal cations defibrillize the amyloid beta-protein fibrils, Neurochem. Res. 22 (1997), 805-809.

[44] B. Mazur-Kolecka, J. Frackowiak, R.T. Carroll and H.M. Wisniewski, Accumulation of Alzheimer amyloid-beta peptide in cultured myocytes is enhanced by serum and reduced by cerebrospinal fluid, J. Neuropathol. Exp. Neurol. 56 (1997), 263272.

[45] B. Mazur-Kolecka, J. Frackowiak, H. Le Vine, 3rd, T. Haske and H.M. Wisniewski, Factors produced by activated macrophages reduce accumulation of Alzheimer's betaamyloid protein in vascular smooth muscle cells, Brain Res. 760 (1997), 255-260. 
[46] A. Chauhan, T. Pirttila, V.P. Chauhan, P. Mehta and H.M Wisniewski, Aggregation of amyloid $\beta$-protein as function of age and apolipoprotein E in normal and Alzheimer's serum, $J$. Neurol. Sci. 154 (1998), 159-163.

[47] P.D. Mehta, A.J. Dalton, S.P. Mehta, K.S. Kim, E.A. Sersen and H.M. Wisniewski, Increased plasma amyloid $\beta$ protein 1-42 levels in Down syndrome, Neurosci. Lett. 241 (1998), $13-16$

[48] J. Wegiel, H.M. Wisniewski, I. Kuchna, M. Tarnawski, E. Badmajew, E. Popovitch, J. Kulczycki, W.K. Dowjat and T. Wisniewski, Cell-type-specific enhancement of amyloid- $\beta$ deposition in a novel presenilin-1 mutation (P117L), J. Neuropathol. Exp. Neurol. 57 (1998), 831-838.

[49] H.M. Wisniewski, M. Sadowski, K. Jakubowska-Sadowska,
M. Tarnawski and J. Wegiel, Diffuse, lake-like amyloid- $\beta$ deposits in the parvopyramidal layer of the presubiculum in Alzheimer disease, J. Neuropathol. Exp. Neurol. 57 (1998), 674-683.

[50] R. Mayeux, M.X. Tang, D.M. Jacobs, J. Manly, K. Bell, C. Merchant, S.A. Small, Y. Stern, H.M. Wisniewski and P.D. Mehta, Plasma amyloid $\beta$-peptide $1-42$ and incipient Alzheimer's disease, Ann. Neurol. 46 (1999), 412-416.

[51] B. Mazur-Kolecka, J. Frackowiak, J. Krzeslowska, N. Ramakrishna, T. Haske, M.R. Emmerling, W. Zhang, K.S. Kim and H.M. Wisniewski, Apolipoprotein E alters metabolism of $\mathrm{A} \beta \mathrm{PP}$ in cells engaged in beta- amyloidosis, J. Neuropathol. Exp. Neurol. 58 (1999), 288-295. 